\title{
Misdiagnosis of an $\alpha$-fetoprotein-producing esophageal carcinoma: A case report and literature review
}

\author{
NINGBO SUN ${ }^{1}$, XUNLU YIN ${ }^{2}$, YUREN ZHONG $^{3}$, XIAOTIAN ZHANG ${ }^{4}$, \\ YAN XIE $^{5}$, XIANGFANG MENG $^{5}$ and QI ZANG $^{5}$ \\ ${ }^{1}$ Department of Thoracic Surgery, Shengli Oilfield Central Hospital, Dongying, Shandong 257034; ${ }^{2}$ Division of Surgery, \\ Graduate Department, Shandong University of Traditional Chinese Medicine, Jinan, Shandong 250014; \\ ${ }^{3}$ Department of Burns and Orthopedics, The First Hospital of Lianyungang, Lianyungang, Jiangsu 222002; \\ ${ }^{4}$ Department of Thoracic Surgery, Dezhou People's Hospital, Dezhou, Shandong 253014; ${ }^{5}$ Department of Thoracic Surgery, \\ Qianfoshan Hospital Affiliated to Shandong University, Jinan, Shandong 250014, P.R. China
}

Received March 29, 2015; Accepted April 29, 2016

DOI: $10.3892 / \mathrm{ol} .2016 .4664$

\begin{abstract}
AFP)-producing esophageal carcinoma is a rare type of esophageal cancer, with its characteristics not yet fully clarified. In the present study, a case of esophageal carcinoma was misdiagnosed as an AFP-producing esophageal carcinoma. The patient was a 50-year-old woman who was referred to Qianfoshan Hospital Affiliated to Shandong University in November 2014 with a 3-month history of progressive dysphagia. A chest computed tomography (CT) scan showed thickening of the wall of the esophagus, corresponding regions of luminal stenosis and massive lymph node swelling around the lesser curvature of the esophagus. A laboratory investigation showed that the serum AFP levels of the patient were elevated to $18.97 \mathrm{ng} / \mathrm{ml}$ (normal range $<12 \mathrm{ng} / \mathrm{ml}$ ). These laboratory investigation findings combined with the aforementioned pathological diagnosis supported a diagnosis of AFP-producing esophageal carcinoma. An abdominal ultrasound was performed and a cystic low-density measuring 5x4 mm was identified. No metastases were revealed in the liver. The boundary of the focal low density was clear, which indicated a clinical diagnosis of liver cyst. A radical esophagectomy was performed on December 5, 2014. Microscopically, the tumor was a moderately differentiated squamous cell carcinoma invading the serous layer, with no hepatoid features. Immunohistochemistry showed that the
\end{abstract}

Correspondence to: Professor Qi Zang, Department of Thoracic Surgery, Qianfoshan Hospital Affiliated to Shandong University, 16766 Jingshi Road, Jinan, Shandong 250014, P.R. China

E-mail: qzang2005@sina.com

Abbreviations: AFP, $\alpha$-fetoprotein; AFP-EC, AFP-producing esophageal cancer; CT, computed tomography; VEGF, vascular endothelial growth factor; PGP, P-glycoprotein

Key words: $\alpha$-fetoprotein, AFP-producing esophageal cancer, esophageal cancer, radical esophagectomy cells were diffusely negative for AFP expression. Histopathological examination revealed the absence of hepatoid features. According to these findings, the tumor was diagnosed as a moderately differentiated squamous cell carcinoma. In the present study, the case of a patient with squamous cell carcinoma that was misdiagnosed as an $\alpha$-fetoprotein-producing esophageal carcinoma was reported, with a review of the literature.

\section{Introduction}

$\alpha$-fetoprotein (AFP) is a protein that is mainly formed by the liver and yolk sac during fetal development, and to a lesser extent, in the fetal gastrointestinal tract $(1,2)$. AFP is detected in fetal serum and the highest serum levels appear between 12 and 15 weeks of gestation, decreasing to normal levels $\sim 1$ year later $(3,4)$. High AFP expression detected in the serum of adults is always associated with liver disease and yolk sac tumors (2-6). AFP-secreting carcinoma is an increasingly recognized tumor, and has been reported in the Japanese literature. Increased AFP expression was detected in malignant tumors of various organs, such as the stomach, lung, pancreas, colon bladder and ovary (7-13). The stomach is one of the most common locations of these tumors (10), whereas AFP-producing esophageal cancer (AFP-EC) is rare (14-17). AFP-producing tumors are usually diagnosed at an advanced stage and have a poor prognosis (18-20).

There are extremely few case reports of AFP-producing esophageal cancers (14-17). Wahren et al (21) reported that 18 patients $(33 \%)$ had elevated serum AFP levels out of 55 patients with esophageal carcinoma, and 5 patients with esophageal carcinoma had an AFP level of $320 \mathrm{ng} / \mathrm{ml}$. The serum AFP levels in patients with adenocarcinoma were evidently increased compared with the levels in patients with squamous cell carcinoma. The serum AFP level can be measured, which may be a useful index for monitoring clinical status, evaluating cure, recurrence or metastases. The serum AFP levels in the patient reported by Kobayashi et al (17) decreased to within normal limits following surgery. This indicates that surgery and chemotherapy are useful therapeutic methods 
A

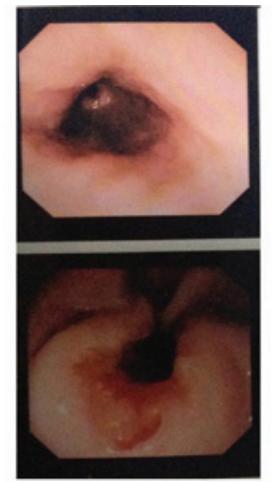

D

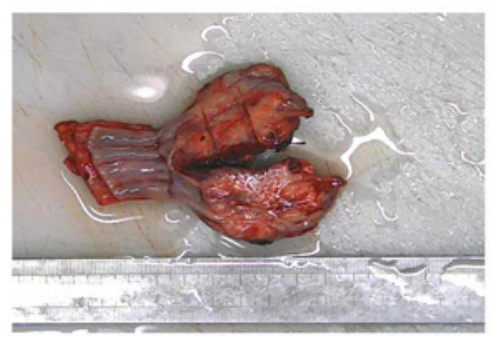

B

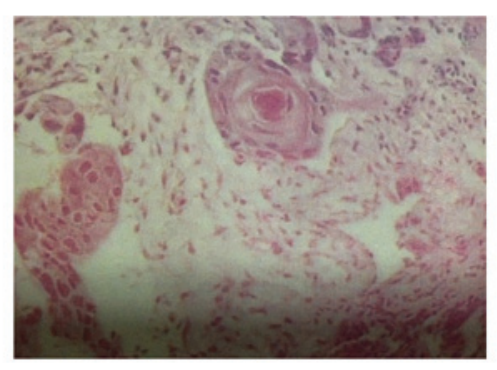

C

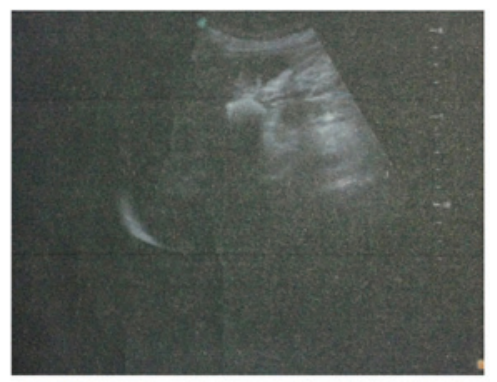

F

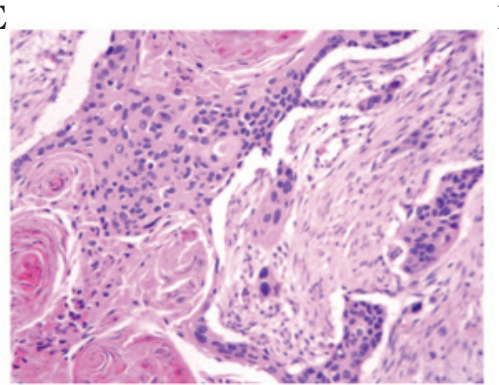

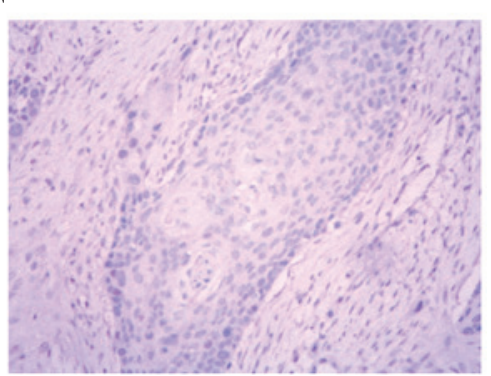

Figure 1. (A) Endoscopy revealed an elevated tumor in the middle and lower segments of the esophagus. (B) In biopsies taken from the area, the tumor was identified as a squamous cell carcinoma. (C) Abdominal ultrasonography was performed and a cystic low density mass measuring $5 \mathrm{x} 4$ mm was identified in the liver. (D) The surgically resected specimen showed an elevated tumor $(5.0 \mathrm{~cm}$ at the maximal diameter) in the middle and lower segment esophagus. (E) Microscopically, the tumor was a moderately differentiated squamous cell carcinoma invading the serous layer, and no hepatoid features were identified (H\&E staining; magnification, x100). (F) Immunohistochemistry showed that the cells were diffusely negative for $\alpha$-fetoprotein (H\&E staining; magnification, $\mathrm{x} 100)$. H\&E, hematoxylin and eosin.

for patients with esophageal carcinoma. It was reported by Wahren et al (21) that there are no significant changes in serum AFP levels subsequent to radiation therapy. AFP-producing upper gastrointestinal tumors are considered to be resistant to chemotherapy (22). The clinical course of numerous patients with AFP-producing esophageal carcinomas is notable for the development of hematogenous metastases to the liver, lung, spleen and brain. The prognosis of these patients is extremely poor. Shimakawa et al (23) and Sawada et al (24) each reported cases of patients that succumbed after 1 year and 4 months, respectively. A case was also reported by Kobayashi et al (17) in which the patient had a satisfactory clinical course for $>3$ years, without further elevation of AFP levels or evidence of metastases on imaging studies.

Due to the poor prognosis of AFP-producing tumors, it is important to make an accurate diagnosis in clinical treatment. In the present study, a case of squamous cell carcinoma that was misdiagnosed as an AFP-producing esophageal carcinoma is reported.

\section{Case report}

A 50-year-old woman presented to a local doctor in August 2014 with a 20-day history of progressive dysphagia. A radiographic examination of the upper gastrointestinal tract revealed an esophageal mass that was clinically similar to esophageal cancer. An endoscopy revealed an elevated tumor in the middle and lower segment of esophagus (Fig. 1A). Biopsies taken from the area 3 days subsequent to presentation revealed a squamous cell carcinoma (Fig. 1B). The patient received one cycle of chemotherapy with oxaliplatin $(140 \mathrm{mg}$; day 1), fluorouracil (1.0 g; days 2-6) and calcium folinate $(0.3 \mathrm{~g}$; days 2-6). However, the progressive dysphagia symptom had worsened due to disease progression. For additional examination and treatment, the patient was referred to Qianfoshan Hospital Affiliated to Shandong University (Jinan, Shandong, China) in November 2014. A chest computed tomography (CT) scan showed thickening of the wall of the esophagus, corresponding regions of luminal stenosis and massive lymph node swelling around the lesser curvature of the esophagus. No primary or metastatic tumors were observed. An abdominal ultrasound was performed and cystic low density measuring $5 \times 4 \mathrm{~mm}$ was identified, and no metastases in the liver were identified (Fig. 1C). The boundary of the focal low density was clear, which indicated a clinical diagnosis of liver cyst. A laboratory investigation showed that the serum AFP levels of the patient were elevated to $18.97 \mathrm{ng} / \mathrm{ml}$ (normal range, $<12 \mathrm{ng} / \mathrm{ml}$ ), the serum carcinoembryonic antigen level was $1.62 \mathrm{ng} / \mathrm{ml}$ (normal range, $<5.0 \mathrm{ng} / \mathrm{ml}$ ), and squamous cell carcinoma (SCC) antigen level was $12.30 \mathrm{ng} / \mathrm{ml}$ (normal range, $1.5 \mathrm{ng} / \mathrm{ml}$ ). Results of other laboratory tests, including and liver function tests, were all within normal limits. These laboratory investigation findings combined with the aforementioned pathological diagnosis supported a diagnosis of AFP-producing squamous cell carcinoma of the esophagus.

A radical esophagectomy was performed on December 5, 2014. The surgically resected specimen showed an elevated tumor $(5.0 \mathrm{~cm}$ at the maximal diameter) in the middle and lower segment of the esophagus (Fig. 1D). Microscopically, the tumor was a moderately differentiated squamous cell carcinoma invading the area of serous layer, with no hepatoid features (Fig. 1E). Immunohistochemistry showed that the 
cells were diffusely negative for AFP (Fig. 1F). One lymph node beside the esophagus showed massive swelling. The tumor was diagnosed as stage IIIA (T3N1M0), according to the American Joint Committee on Cancer guidelines (25).

Postoperatively, the patient was treated with four cycles of nedaplatin (200 mg; day 1, repeated on day 21) plus gemcitabine (1,500 mg; days 1 and 8 , repeated on day 21), and has been free of recurrence for 4 months. However, the serum AFP levels had increased between 13.39 and $17.39 \mathrm{ng} / \mathrm{ml}$, and had not decreased to the normal range. These findings show that the increase in AFP levels was not associated with esophageal cancer.

Written informed consent was obtained from the patient for publication of the present study and any accompanying images.

\section{Discussion}

AFP is a type of protein that is mainly formed by the liver and yolk sac during fetal development, and to a lesser extent, in the fetal gastrointestinal tract $(1,2)$. AFP is detected in the fetal serum and the highest serum levels majority of appear between 12 and 15 weeks of pregnancy and $\sim 1$ year later the levels decrease to the normal range $(3,4)$. High AFP levels are detected in the serum with liver disease and yolk sac tumors (2-6). AFP-secreting carcinoma is an increasingly recognized tumor, and the main part in reported in the Japanese literature. AFP rising was detected in malignant tumors of different organs, for example, the stomach, lung, pancreas, colon bladder, and ovary (7-13). The stomach is one of the most common locations of such tumors (10), whereas AFP-EC is rare.

In tumors, the molecular mechanism associated with AFP expression is poorly understood. In upper gastrointestinal tumors, it proposed that the increase in AFP levels is due to an absence of AT motif binding factor I, which is a transcription factor that binds to the AFP-regulatory element and downregulates the AFP gene (26). In AFP-producing tumors, human albumin mRNA in situ hybridization showed cytoplasmic positivity and is considered to be additional evidence of hepatocellular differentiation of these tumors (27). Previously, certain factors associated with mitosis, cell movement, proliferative activity and tumor progression, such as hepatocyte growth factor (HGF), Ki-67 and its receptor, vascular endothelial growth factor (VEGF), and c-Met and its isoform VEGF-C, were found to be highly expressed in AFP-producing tumors, and these factors may be associated with the poor prognosis of this tumor (28-30). Furthermore, AFP-producing upper gastrointestinal tumors are considered to be resistant to chemotherapy (22).

P-glycoprotein (PGP), which is associated with the phenotypic expression of multidrug resistance in cancerous tissue, was found to be overexpressed in AFP-producing tumors. Therefore, the observed drug resistance and frequent recurrence may be explained by the presence of PGP (31). Chang et al (22) proposed that even if no metastasis is present preoperatively, liver metastasis frequently occur within a year of surgery. In addition, AFP-producing tumors were found to have an increased likelihood of expression of chemoresistance-associated proteins. However, chemotherapy has been reported to be effective in several patients $(18-20,32)$. Due to the poor prognosis of this type of tumor, accurate diagnosis is necessary, and clinicians should consider more effective treatments of this particular type of AFP-producing tumor in patients with good performance status, and recommend for curative resection and further chemotherapy.

\section{References}

1. Gitlin D, Pericelli A and Gitlin GM: Synthesis of -fetoprotein by liver, yolk, sac and gastrointestinal tract of the human conceptus. Cancer Res 32: 979-982, 1972.

2. Babali A, Cakal E, Purnak T, Bıyıkoğlu I, Cakal B, Yüksel O and Köklü S: Serum $\alpha$-fetoprotein levels in liver steatosis. Hepatol Int 3: 551-555, 2009.

3. Mizejewski GJ: Levels of alpha-fetoprotein during pregnancy and early infancy in normal and disease states. Obstet Gynecol Surv 58: 804-826, 2003

4. Breborowicz J, Mackiewicz A and Breborowicz D: Microheterogeneity of alpha-fetoprotein in patient serum as demonstrated by lectin affino-electrophoresis. Scand J Immunol 14: 15-20, 1981.

5. Ezaki T, Yukaya H, Ogawa Y, Chang YC and Nagasue N: Evaluation of alpha-fetoprotein level without evidence of recurrence after hepatectomy for hepatocellular carcinoma. Cancer 61: 1880-1883, 1988

6. Ganjei P, Nadji M, Albores-Saavedra J and Morales AR: Histologic markers in primary and metastatic tumors of the liver. Cancer 62: 1994-1998, 1988.

7. Yamagata T, Yamagata Y, Nakanishi M, Matsunaga K, Minakata $\mathrm{Y}$ and Ichinose M: A case of primary lung cancer producing alpha-fetoprotein. Can Respir J 11: 504-506, 2004.

8. Hamanaka W, Yoneda S, Shirakusa T, Shirahama H, Tashiro Y, Iwasaki A, Shiraishi T and Tsuru H: Alpha-fetoprotein (AFP)-producing adrenocortical carcinoma-long survival with various therapeutic strategies including a lung resection: Report of a case. Surg Today 38: 275-278, 2008.

9. Matsueda K, Yamamoto H, Yoshida Y and Notohara K: Hepatoid carcinoma of the pancreas producing protein induced by vitamin $\mathrm{K}$ absence or antagonist II (PIVKA-II) and alpha-fetoprotein (AFP). J Gastroenterol 41: 1011-1019, 2006.

10. Kinjo T, Taniguchi H, Kushima R, Sekine S, Oda I, Saka M, Gotoda T, Kinjo F, Fujita J and Shimoda T: Histologic and immunohistochemical analyses of $\alpha$-fetoprotein-producing cancer of the stomach. Am J Surg Pathol 36: 56-65, 2012.

11. Cappetta A, Bergamo F, Mescoli C, Lonardi S, Rugge M and Zagonel V: Hepatoid adenocarcinoma of the colon: What should we target? Pathol Oncol Res 18: 93-96, 2012.

12. Kawamura N, Hatano K, Kakuta Y, Takada T, Hara T and Yamaguchi S: A case of hepatoid adenocarcinoma of the urinary bladder. Hinyokika Kiyo 55: 619-622, 2009.

13. Isonishi S, Ogura A, Kiyokawa T, Suzuki M, Kunito S, Hirama M, Tachibana T, Ochiai K and Tanaka T: Alpha-fetoprotein (AFP)-producing ovarian tumor in an elderly woman. Int J Clin Oncol 14: 70-73, 2009.

14. Chen YY, Hsu WH, Hu HM, Wu DC and Lin WY: A case of alpha-fetoprotein-producing esophageal adenocarcinoma. Kaohsiung J Med Sci 29: 106-110, 2013.

15. Kripp M, Ströbel P, Dinter D, Lukan N, Hochhaus A and Hofheinz RD: Alpha-fetoprotein expressing metastastic adenocarcinoma of the esophago-gastric junction responding favorably to capecitabine and oxaliplatin. Anticancer Drugs 20: 75-78, 2009.

16. Kawai H, Sekine S, Sanada T, Andoh T, Takechi Y and Okada S: Alpha-fetoprotein-producing esophageal carcinoma: A case report. Anticancer Res 23: 3837-3840, 2003.

17. Kobayashi N, Ohbu M, Kuroyama S, Kikuchi S, Shimao H, Mitomi $\mathrm{H}$ and Kakita A: Alpha-Fetoprotein-producing esophageal adenocarcinoma: Report of a case. Surg Today 31: 915-919, 2001

18. Takeuchi M, Yamaoka S, Matsumura K, et al: An alpha-fetoprotein producing gastric carcinoma with hepatoid features. A case report of hepatoid adenocarcinoma of the stomach. Gastroenterol Endosc 31: 442-448, 1989 (In Japanese).

19. Nemoto A, Goshima H, Tanigawa K, et al: A case of AFP-producing gastric cancer with multiple liver metastasisn showing marked improvement by hepatoarterial infusion with cisplatin. Mie Igaku 42: 84-94, 1998 (In Japanese). 
20. Suzuki Y, Watanabe M, Nonaka H, Kase H, Tokura N Kikuchi M, Matsumoto H, Kobayashi K, Akima M and Yoshio T: A case of advanced gastric carcinoma producing alpha-fetoprotein with multiple liver metastasis in which intrahepatic chemotheraphy was effective postgastrectomy. Jpn J Gastroenterol Surg 32: 2365-2369, 1999 (In Japanese).

21. Wahren B, Harmenberg J, Edsmyr F, Jakobsson P and Ingimarsson S: Possible tumour markers in patients with oesophagus cancer. Scand J Gastroenterol 14: 361-365, 1979.

22. Chang YC, Nagasue N, Kohono H, Ohiwa K, Yamanoi A and Nakamura T: Xenotransplantation of alpha-fetoprotein-producing gastric cancers into nude mice: Characteristics and responses to chemotherapy. Cancer 69: 872-877, 1992.

23. Shimakawa T, Ogawa K, Naritaka Y, Wagatsuma Y, Katsube T, Hamaguchi K, Konno S, Aiba M and Kajiwara T: Alphafetoprotein producing Barrett's esophageal adenocarcinoma: A case report. Anticancer Res 19: 4369-4373, 1999.

24. Sawada H, Watanabe A, Yamada Y, Yano T, Nakano H and Konishi Y: Alpha-fetoprotein producing esophageal adenocarcinoma: Report of a case. Surg Today 23: 1103-1107, 1993.

25. Sobin LH, Gospodarowicz M and Wittekind C (eds): Oesophagus including oesophagogastric junction. In TNM Classification of Malignant Tumours. 7th edition. Wiley-Blackwell, Oxford, pp66-72, 2009.
26. Kataoka H, Miura Y, Joh T, Seno K, Tada T, Tamaoki T, Nakabayashi H, Kawaguchi M, Asai K, Kato T and Itoh M: Alpha-fetoprotein producing gastric cancer lacks transcriptionalfactor ATBF1. Oncogene 20: 869-873, 2001.

27. Foschini MP, Baccarini P, Dal Monte PR, Sinard J, Eusebi V and Rosai J: Albumin gene expression in adenocarcinomas with hepatoid differentiation. Virchows Arch 433: 537-541, 1998.

28. Koide N, Nishio A, Igarashi J, Kajikawa S, Adachi W and Amano J: Alpha-fetoprotein-producing gastric cancer: Histochemical analysis of cell proliferation, apoptosis, and angiogenesis. Am J Gastroenterol 94: 1658-1663, 1999.

29. Amemiya H, Kono K, Mori Y, Takahashi A, Ichihara F, Iizuka H, Sekikawa T and Matsumoto Y: High frequency of c-Met expression in gastric cancers producing alpha-fetoprotein. Oncology 59: 145-151, 2000.

30. Kamei S, Kono K, Amemiya H, Takahashi A, Sugai H, Ichihara F, Fujii $\mathrm{H}$ and Matsumoto Y: Evaluation of VEGF and VEGF-C expression in gastric cancer cells producing alpha-fetoprotein. J Gastroenterol 38: 540-547, 2003.

31. Dhar DK, Nagasue N, Yoshimura H, Tachibana M, Tahara H, Matsuura $\mathrm{H}$, Abe S, Chang YC and Nakamura T: Overexpression of P-glycoprotein in untreated AFP-producing gastric carcinoma. J Surg Oncol 60: 50-54, 1995.

32. Ohashi N, Goshima H, Yamazaki H, et al: A case report of so-called hepatoid adenocarcinoma of the stomach without liver metastasis. Ringe (J Clin Surg) 43: 1537-1541, 1988 (In Japanese). 